\title{
A Extrafiscalidade como Instrumento de Proteção do Meio Ambiente Ecologicamente Equilibrado
}

\author{
Extraficality as a Means to Protection of an Ecologically Balanced Enviroment
}

\section{CAROLINA SCHROEDER ALEXANDRINO}

Advogada, Bacharel em Direito - Ciências Jurídicas e Sociais pela Unisinos, Bacharel Laureada, premiada pelo primeiro lugar no Curso de Direito da Unisinos e como aluna destaque entre os formandos. Possui especialização em Advocacia Tributária pela ESA/RS, curso de extensão certificado pela Instituição Faculdade IDC: Extensão em Direito Previdenciário, curso de extensão certificado pelo escritório especializado em Consultoria, Empresarial Scaliilli.fmv: Gestão de Crise, Falências e Recuperação Judicial.

\section{MARCIANO BUFFON}

Doutor em Direito com ênfase em Direito do Estado pela Unisinos, com período de pesquisa na Universidade de Coimbra, Mestre em Direito Público, Advogado Tributarista, com especialização em Direito Empresarial, Professor de Direito Tributário na Unisinos (São Leopoldo/RS) e em cursos de especialização em Direito Tributário em outras instituições, Professor no Programa de Pós-Graduação em Direito da Unisinos, Sócio/Consultor jurídico-fiscal do escritório Buffon \& Furlan Advogados Associados, Membro do Conselho Técnico de Assuntos Tributários, Legais e Financeiros da Federação das Indústrias do Estado do Rio Grande do Sul - Fiergs.

Submissão: 11.05 .2015

Decisão Editorial: 21.07.2015

Comunicação ao autor: 21.07.2015

RESUMO: 0 presente estudo busca demonstrar como a tributação, com finalidade não fiscal, pode consubstanciar-se em um meio eficaz de proteção do meio ambiente ecologicamente equilibrado. Nesse escopo, analisa-se a extrafiscalidade, que objetiva a realização de valores que ultrapassam a mera arrecadação de tributos; como instrumento de preservação ambiental dentro de uma sociedade reflexiva, de risco. Para tanto, a extrafiscalidade é demonstrada em dois principais segmentos: a) pelos impostos e b) por meio dos benefícios fiscais. Assim, traça-se um elo entre o Direito Tributário e o Direito Ambiental a partir do estudo da extrafiscalidade como ferramenta de proteção do meio ambiente.

PALAVRAS-CHAVE: Extrafiscalidade; tributação; direito ambiental; gerenciamento dos riscos; políticas públicas. 
ABSTRACT: The present study aims to demonstrate how the taxation, with non fiscal ends, can turn into an effective way to protect the enviroment, ecologically balanced. At this point, the extrafiscality, witch tenses to produce values that are more than the simple collection os taxes, is analised as the means to an enviroment preservation, in a risk reflective society. There for, the extrafiscality is demonstrated in two main segments: a) through taxes and b) through taxes benefits. As such, this study builds a link through the Tax Law and the Enviroment Law, by the study of the extrafiscality as a tool for the enviroment protection.

KEYWORDS: Extrafiscality; taxation; enviroment law; management of risks; public policy

SUMÁRIO: Introdução; 10 elo entre o direito ambiental e o direito tributário, sendo este para manter a subsistência do bem juridicamente tutelado por aquele; $1.1 \mathrm{~A}$ extrafiscalidade em harmonia com a Constituição brasileira na busca por um meio ambiente ecologicamente equilibrado; 2 Manifestação da extrafiscalidade mediante os benefícios fiscais; 3 Tributação ambiental: onerações oriundas dos impostos extrafiscais na busca de um meio ambiente ecologicamente equilibrado; Considerações finais; Referências.

\section{INTRODUÇÃO}

A necessidade de mecanismos que contribuam para com a proteção do meio ambiente e gerenciamento dos riscos ambientais são de suma importância, haja vista a atual sociedade ser considerada reflexiva, na qual os riscos e os perigos são globais, e suas consequências, impossíveis de prever e descrever aos sentidos humanos. A Constituição Brasileira de 1988 tem capítulo próprio para tratar sobre o meio ambiente, no entanto, acaba sendo complementada por outros dispositivos esparsos que, de forma direta ou indireta, têm como intuito a preservação ambiental.

Nessa ótica, a busca por um meio ecologicamente equilibrado pode ser perseguida por outros ramos do direito, como o Direito Tributário, que tem de estar em sintonia com o Direito Econômico, Social e Ambiental, para o alcance do desenvolvimento sustentável. Dentro desse contexto, dar-se-á maior atenção à proteção ambiental mediante a utilização da denominada extrafiscalidade, a fim de demonstrar que a tributação assume papel importante, quando utilizada para efetivar direitos e garantias fundamentais, como o meio ambiente ecologicamente equilibrado que, contemporaneamente, passa a ser de extrema necessidade para mantença de qualquer espécie de vida.

\section{ELO ENTRE 0 DIREITO AMBIENTAL E 0 DIREITO TRIBUTÁRIO, SENDO ESTE PARA MANTER A SUBSISTÊNCIA DO BEM JURIDICAMENTE TUTELADO POR AQUELE}

O Direito Ambiental tem como objetivo estudar a relação entre o homem e o mundo, analisando os problemas existentes nesta relação. Por tal motivo, transmite uma mensagem de antecipação, gerenciando riscos mediante a pre- 
venção, a precaução e a equidade intergeracional, haja vista a impossibilidade de recuperação de alguns ecossistemas, quando afetados.

Uma das características da disciplina é ser um direito sistematizador, pois, ainda que haja tutela de bens juridicamente considerados (água, solo, ar etc.), eles se relacionam ${ }^{1}$, o que faz do Direito Ambiental um grande sistema. Há uma interligação de seus temas e, por tal motivo, ele busca elementos em outras disciplinas do Direito ${ }^{2}$. Outra característica de tal direito é a ideia de ser ele presente e futuro ${ }^{3}$, ou seja, passa uma mensagem de antecipação, que surge com maior clareza quando se trata dos princípios gerais da matéria jurídico ambiental, principalmente no tocante ao princípio da precaução e seu viés solidário, quando da preservação ambiental para futuras gerações ${ }^{4}$. Não obstante, cumpre destacar que o Direito a um meio ambiente sadio, apesar de não estar expressamente previsto no art. $5^{\circ}$ da Constituição Federal, é reconhecido como direito fundamental do cidadão ${ }^{5}$.

A previsão de proteção constitucional do meio ambiente está disposta no art. 225 da Constituição, assegurando a todos o direito a um meio ambiente ecologicamente equilibrado ${ }^{6}$, tendo estes (todos) o dever de proteger o meio ambiente para as atuais e futuras gerações. São direitos de todos ${ }^{7}$, pois ultrapassam as individualidades, são heterogêneos e, portanto, possuem natureza de direito difuso, de terceira geração/dimensão ${ }^{8-9}$.

Assim, a proteção ambiental não compete apenas ao Poder Público, mas também a toda sociedade. Devido ao fato do meio ambiente ecologicamente equilibrado ser um direito fundamental de terceira dimensão, outros ramos do direito podem conter instrumentos aptos à proteção, entre eles o Direito Tributário ${ }^{10}$.

1 MACHADO, Paulo Affonso Leme. Direito ambiental brasileiro. 18. ed. São Paulo: Malheiros, 2010. p. 54-55.

2 Idem, p. 55.

3 CARVALHO, Délton Winter de. Dano ambiental futuro: a responsabilização civil pelo risco ambiental. Rio de Janeiro: Forense Universitária, 2008. p. 44.

4 FIORILLO, Celso Antonio Pacheco. Curso de direito ambiental brasileiro. 13. ed. São Paulo: Saraiva, 2012. p. 75.

5 FREITAS, Vladimir Passos de. A Constituição Federal e a efetividade das normas ambientais. 2. ed. São Paulo: Revista dos Tribunais, 2002. p. 23.

6 Cumpre salientar o conceito de meio ambiente ecologicamente equilibrado para Affonso Leme Machado, in verbis: "O equilíbrio ecológico não significa uma permanente inalterabilidade das condições naturais. Contudo, a harmonia ou a proporção e a sanidade entre vários elementos que compõem a ecologia população, comunidades, ecossistemas e bioesfera - hão de ser buscadas intensamente pelo Poder Público, pela coletividade e por todas as pessoas" (MACHADO, Paulo Affonso Leme. Op. cit., p. 132).

7 Idem, p. 131.

8 BOBBIO, Norberto. A era dos direitos. Rio de Janeiro: Campus, 1992. p. 6.

9 GARCIA, Wander. Direito ambiental. São Paulo: Premier, 2009. p. 17.

10 BUFFON, Marciano. Tributação e dignidade humana: entre os direitos e deveres fundamentais. Porto Alegre: Livraria do Advogado, 2009. p. 218. 
Sabe-se que expressivo percentual da parcela econômica estatal só é possível por meio da arrecadação tributária $\mathrm{e}^{11}$, portanto, a tributação pode intervir na economia com estímulo ou desestímulo de determinadas atividades ou condutas, de forma direta ou indireta, a fim de buscar concretizar objetivos constitucionais $^{12}$. Por tal motivo, também compete ao Direito Tributário orientar a atividade econômica para que ela possa trazer benefícios à sociedade, o que ocorre quando a tributação deixa de estar voltada exclusivamente para a obtenção de recursos ao Estado, servindo também como "[...] instrumento de repartição de riquezas e desenvolvimento econômico"13, ou seja, por meio de políticas tributárias é possível que os direitos fundamentais econômicos, sociais e culturais se tornem mais eficazes ${ }^{14}$.

Entre as possibilidades do Direito Tributário contribuir para com a preservação ambiental, a mais adequada é aquela que tem como objetivo intervir no domínio econômico, estimulando ou desestimulando determinados comportamentos na busca de resultados diversos da simples arrecadação ${ }^{15}$, tal mecanismo é chamado de extrafiscalidade.

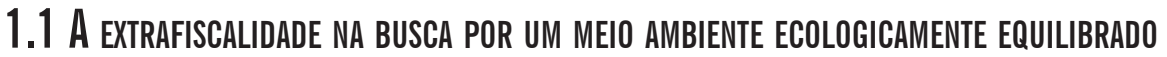

O objetivo do Estado, em um prisma constitucional, é a busca pelo bem comum, e para que seja possível concretizar tal objetivo, a arrecadação de tributos se faz necessária. Os recursos que o Estado necessita para atingir seus fins são comumente provenientes da tributação fiscal, entretanto a tributação pode apresentar outro contorno que não aquele com finalidade puramente arrecadatória. Trata-se de arrecadar intervindo na área econômica e social, o que se denominada extrafiscalidade.

Mesmo que a atividade econômica não seja exercida pelo ente estatal, é possível que, mediante a tributação, nela intervenha, buscando com isso fins diversos daqueles puramente arrecadatórios ${ }^{16}$. Destarte, fugindo da ideia pura e simples de arrecadação estatal, tem-se a tributação extrafiscal, voltada a um viés social e, porque não, solidário.

11 MARTINS, Ives Gandra da Silva. Teoria da imposição tributária. 2. ed. rev. e atual. São Paulo: LTr, 1998. p. 48.

12 CARDOSO, Tatiana de Almeida Freitas Rodrigues. Por uma tutela efetiva ao meio ambiente: a aplicação da law \& economics para combater a tragédia dos bens comuns. 2012. f. 113. Dissertação de Mestrado pelo Programa de Pós-Graduação em Direito da Universidade do Vale do Rio dos Sinos, São Leopoldo/RS, 2012. Disponível em: <http://biblioteca.asav.org.br/vinculos/000000/000000A1.pdf>. Acesso em: 7 maio 2015.

13 BOTELHO, Werther. Da tributação e sua destinação. Belo Horizonte: Del Rey, 1994. p. 34-35.

14 BUFFON, Marciano. Op. cit., p. 229.

15 MACHADO, Hugo de Brito. Curso de direito tributário. 31. ed. rev., atual. e ampl. São Paulo: Malheiros, 2010. p. 56.

16 Idem, p. 74. 
Os mecanismos existentes para que haja um sistema tributário com cunho social persistem e vêm ganhando força, principalmente quando da tutela de direitos fundamentais de terceira dimensão ${ }^{17}$, que se apresenta como um sistema oriundo do ente estatal a fim de incentivar benéficas atividades, como, por exemplo, aquelas que possam reduzir a degradação ambiental ${ }^{18}$. A partir do sistema jurídico-tributário, é possível vislumbrar que a tributação tem dupla finalidade e dupla razão de existir, são elas: a) auferir recursos para que o Estado subsista, o que significa falar de "fiscalidade"; e b) garantir a realização dos direitos fundamentais dos cidadãos, os verdadeiros fins do Estado, o que significa falar de extrafiscalidade, considerando-a como os objetivos valorativos da tributação ${ }^{19}$.

Independente das críticas acerca do sistema tributário brasileiro, é inegável que a tributação pode ser empregada para reduzir desigualdades sociais e concretizar os objetivos fundamentais dispostos na Constituição ${ }^{20}$, uma vez que "[...] não pode ser vista como uma mera 'declaração de boas intenções' ou um texto programático" 21 .

Quando se transfere àqueles com maior capacidade contributiva o custeio dos serviços públicos, mediante progressiva incidência de tributos sobre a renda, fato gerador do Imposto de Renda Pessoa Física ou Jurídica (IRPF/IRPJ), é possível identificar efeitos extrafiscais indiretos, pois o objetivo não é induzir ou reprimir comportamentos, mas sim distribuir renda, conforme preceitos constitucionais. Assim, a progressividade pode ser vista como fiscal, consequência do princípio da capacidade contributiva, e extrafiscal, objetivando fomentar princípios da ordem econômica, como a função social da propriedade ${ }^{22}$.

Ademais, também é importante a opinião retirada da doutrina de Carrazza, de que é possível extrair sentidos extrafiscais de impostos que eventualmente não possam ser progressivos, pois a Constituição brasileira não permite que tenham caráter pessoal, pois, de certa forma, podem influenciar no comportamento da sociedade ${ }^{23}$. Trata-se dos impostos indiretos, como o Impos-

17 "Há de se concordar, porém, que essa classificação serve mais como instrumento pedagógico do que como elemento apto a fazer uma distinção estanque das ditas dimensões ou gerações de direitos fundamentais, assim denominadas para que seja possível compreender o processo histórico e como os direitos fundamentais adquiriram o grau de sofisticação que ora se contesta." (BUFFON, Marciano. Op. cit., p. 135)

18 MATTHES, Rafael Antonietti. Extrafiscalidade como instrumento de proteção ambiental no Brasil. Veredas do Direito, Belo Horizonte, v. 8, n. 16, p. 47-48, jul./dez. 2011.

19 GOUVÊA, Marcus de Freitas. Questões relevantes acerca da extrafiscalidade no direito tributário. Interesse Público, Sapucaia do Sul, n. 34, p. 180, 2005.

20 BUFFON, Marciano. Op. cit., p. 116.

21 Idem, p. 110.

22 CARRAZZA, Roque Antônio. A progressividade na ordem tributária. Revista de Direito Tributário, São Paulo, v. 64 , p. $47-48,1994$

23 Idem, p. 53. 
to sobre Produto Industrializado (IPI), que pode ter sua carga tributária alterada conforme a essencialidade do produto industrializado ${ }^{24}$.

O Imposto sobre Operações de Crédito, Câmbio e Seguro, ou relativas a Títulos ou Valores Mobiliários (IOF) também é um bom exemplo de imposto com caráter extrafiscal, pois tem como objetivo regular o mercado financeiro, desestimulando determinados negócios ou desonerando determinadas atividades, com a finalidade de prestigiá-las ${ }^{25}$.

Assim, ainda que a Constituição determine direitos fundamentais a serem efetivados, nem sempre serão concretizados em função da transferência de importâncias financeiras do contribuinte ao Estado, podendo ser almejados, também, por estímulos ou desestímulos tributários concedidos à sociedade, ou a intervenção estatal por meio da tributação ${ }^{26}$. Com a implementação das medidas extrafiscais, vislumbra-se a atuação reguladora do Estado na área econômica, política e cultural, fazendo com que o dever de pagar tributos auxilie no desenvolvimento social ${ }^{27}$.

Para a doutrina portuguesa, lastreada pelos ensinamentos de Cassalta Nabais, a extrafiscalidade se expande por dois grandes domínios: impostos e benefícios fiscais, sendo que cada um deles se utiliza da tributação de forma distinta para intervir ou conformar o meio social. Os impostos extrafiscais têm como objetivo dissuadir ou evitar determinados comportamentos; já os benefícios fiscais buscam fomentar, incentivar ou estimular determinados comportamentos. Contudo, tanto a mudança comportamental como sua mantença buscam a proteção de interesses comuns, típicos do Estado de Bem-Estar Social ${ }^{28}$ característico da atual Constituição da República.

\section{MANIFESTAÇÃO DA EXTRAFISCALIDADE MEDIANTE OS BENEFÍCIOS FISCAIS}

A efetividade da extrafiscalidade é vislumbrada com maior precisão no domínio dos benefícios fiscais, isso porque os impostos, mesmo que revestidos de caráter extrafiscal, acabam por se conformar com as normas e princípios específicos e atinentes à sua existência, caracterizando-se como medidas de po-

24 Idem, ibidem.

25 MARAFON, Plínio José. IOF. In: MARTINS, Ives Gandra da Silva (coord.). Curso de Direito Tributário. 8. ed. São Paulo: Saraiva, v. 2, 2001.p. 466.

26 GOUVÊA, Marcus de Freitas. Op. cit., p. 190-191.

27 DEUD, Maria Luiza Bello. Extrafiscalidade e políticas públicas de desenvolvimento. Revista Jurídica Empresarial, Porto Alegre, v. 3, n. 18, p. 27, jan./fev. 2011.

28 "Com a Constituição de Weimar e o fim do Estado Liberal do século XVIII, deu-se início ao Estado Contemporâneo, também nominado de Estado do Bem-Estar Social que originou os direitos de segunda dimensão, são eles direitos sociais, culturais e econômicos. No íntimo do Estado de Bem-Estar Social há uma visão macro da sociedade, ou seja, o cidadão é visto de forma global e não de modo individualizado, por tal motivo os interesses são comuns, competindo ao Estado atendê-los." (Idem, p. 29) 
lítica fiscal ${ }^{29}$. Contrariamente, os benefícios fiscais possuem nítida configuração de medidas de política econômica e social, pois são atos de caráter excepcional que têm como objetivo amparar interesses públicos de significativa relevância, superiores àqueles caracterizados pela tributação ${ }^{30}$.

Os benefícios fiscais podem ser compreendidos como isenções, redução de alíquotas, redução de base de cálculo e, até mesmo, diferimento. A Lei no 4.320/1964, nominada como Lei de Responsabilidade Financeira, positiva normas gerais sobre o controle dos efeitos dos benefícios, no entanto, não traz o conceito do que são os referidos benefícios ${ }^{31}$. A Constituição Federal brasileira não apresentou um conceito rico em detalhes sobre os benefícios fiscais ${ }^{32}$, sendo possível compreendê-los por meio daqueles institutos tradicionais do Direito Tributário.

No tocante à preservação do meio ambiente para as atuais e futuras gerações, esta pode se efetivar mediante os benefícios fiscais de caráter extrafiscal, sendo que tal renúncia de receitas possui, dentro da lógica de direito ambiental, caráter preventivo, pois beneficia àqueles que se preocupam com a proteção ambiental e não causam lesões ao meio ambiente ${ }^{33}$. Ademais, a referida renúncia, total ou parcial, não causa prejuízos ao Poder Público, pois ele acaba sendo compensado no futuro, quando deixa de "[...] praticar despesas para manter ou recuperar danos de várias ordens ocorridos no meio ambiente por falta de um devido tratamento que nosso ordenamento acaba nos oferecendo" ${ }^{34}$.

Por tal motivo, não restam dúvidas que determinados benefícios fiscais brasileiros são dotados de finalidade extrafiscal, pois têm como objetivo alcançar o desenvolvimento do País ${ }^{35}$, viabilizando a proteção de direitos constitucionalmente previstos. Para tanto, quando da aplicação dos benefícios fiscais para fins econômicos e sociais, leva-se em consideração a proibição de excessos e a primazia pela aplicabilidade do princípio da igualdade, sob a análise da necessidade e adequação na busca pelo objetivo econômico social pretendido ${ }^{36}$.

29 NABAIS, José Casalta. $O$ dever fundamental de pagar impostos: contributo para a compreensão constitucional do estado fiscal contemporâneo. Coimbra: Almedina, 2009. p. 632-633.

30 Idem, p. 633.

31 HENRIQUES, Elcio Fiori. Os benefícios fiscais no direito financeiro e orçamentário: o gasto tributário no direito brasileiro. São Paulo: Quartier Latin, 2010. p. 125.

32 Idem, p. 120.

33 BERNARDI, Renato. Tributação ecológica: o uso ambiental da extrafiscalidade e da seletividade tributárias. Revista Magister de Direito Ambiental e Urbanístico, Porto Alegre, v. 3, n. 15, p. 74, dez. 2007.

34 SALIBA, Ricardo Berzosa. Fundamentos do direito tributário ambiental. São Paulo: Quarter Latin, 2005. p. 324.

35 DEUD, Maria Luiza Bello. Op. cit., p. 27.

36 NABAIS, José Casalta. Op. cit., p. 696. 


\section{TRIBUTAÇÃO AMBIENTAL: ONERAÇÕES ORIUNDAS DOS IMPOSTOS EXTRAFISCAIS NA BUSCA DE UM MEIO AMBIENTE ECOLOGICAMENTE EQUILIBRADO}

Entre os impostos, taxas e contribuições, a melhor espécie tributária que pode ser utilizada como instrumento extrafiscal é a primeira, o imposto. Cumpre salientar que, as onerações tributárias empregadas para fins de proteção ambiental, não têm o intuito de punir os poluidores pelo ato ilícito cometido, pois, caso fosse, estar-se-ia transformando o tributo em uma forma de penalidade $^{37}$, o que é vedado pelo art. $3^{\circ}$ do CTN. Outrossim, a tributação ambiental, bem como ocorre com o princípio poluidor-pagador, também não tem como objetivo trazer a ideia de que aquele que paga pode poluir, mas sim servir como medida promissora na busca do desenvolvimento sustentável ${ }^{38}$, ou seja, buscar o desenvolvimento econômico aliado à preservação do meio ambiente ${ }^{39}$.

O imposto acaba sendo a melhor espécie tributária a ser utilizada com finalidade extrafiscal, por ser tributo que melhor estimula ou desestimula condutas. A gradação de alíquotas, alterações da base de cálculo, isenções e diferimento podem impulsionar a produção e a circulação de produtos ambientalmente corretos, bem como a prestação de serviços ecologicamente sustentáveis, além de desestimular condutas lesivas ou potencialmente lesivas ao meio ambiente ${ }^{40}$.

As onerações com fins extrafiscais podem ser verificadas comumente nos impostos. A potencialidade poluidora de cada produto importado, por exemplo, serve como parâmetro para majoração do Imposto de Importação (II), servindo como forma de coibir a entrada de mercadorias potencialmente nocivas ao meio ambiente, em consonância com o Princípio da Prevenção e Precaução. Corroborando com o ora aludido, nesse sentido, Oliveira Souza ${ }^{41}$ afirma que a majoração do II com fins ambientais não pode apenas se ater à potencialidade poluidora do produto importado, mas também às condições em que estes produtos são produzidos, haja vista não ser possível dimensionar, geograficamente, os impactos ambientais.

Nesse mesmo sentido, onerar o IPI dos produtos industrializados que causam impactos ambientais também se desvela como medida extrafiscal em prol do meio ambiente. Todavia, tal possibilidade não é aceita de forma unânime pela doutrina, havendo aqueles que discordam, como Gonçalves, ao afirmar

37 MACHADO, Hugo de Brito. Op. cit., p. 56.

38 FAZOLLI, Silvio Alexandre. Princípios ambientais tributários e extrafiscalidade. Revista de Direito Ambiental, São Paulo, n. 34, p. 78-83, 2004.

39 SOUZA, James José Marins de; TEODOROVICZ, Jeferson. Extrafiscalidade socioambiental. Revista Tributária e de Finanças Públicas, São Paulo, v. 18, n. 90, p. 103, jan./fev. 2010.

40 SOUZA, Jorge Henrique de Oliveira. Tributação e meio ambiente: as espécies tributárias e sua utilização para alcance de um meio ambiente ecologicamente equilibrado. Belo Horizonte: Del Rey, 2009. p. 143.

41 Idem, p. 149. 
que a majoração de alíquotas com fins ambientais fere previsão constitucional, pois a diferenciação de alíquota do IPI obedece apenas ao Princípio da Seletividade, que se pauta exclusivamente na essencialidade do produto. Aplicar tal diferenciação para além da seletividade do produto acabaria violando a capacidade contributiva ${ }^{42}$.

Entretanto, seguindo os ensinamentos de Souza e Bottallo, acredita-se que a distinção de alíquotas do IPI não pode ser analisada de forma restrita, considerando essencial apenas aquilo que o salário-mínimo deveria garantir, como moradia, alimentação, educação, saúde, lazer, vestuário, higiene, transporte e Previdência Social ${ }^{43-44}$, conforme o art. $7^{\circ}$ da Constituição. Necessita-se fazer uma interpretação aberta do texto Constitucional, de modo que a proteção do meio ambiente, prevista no art. 225, seja compreendida ao lado das garantias mencionadas no art. 7º justificando, contudo, a gradação da alíquota de IPI aos produtos industrializados que causam negativos impactos ambientais, bem como a desoneração da alíquota àqueles que contribuem para um meio ambiente ecologicamente equilibrado.

Dessa forma, é possível afirmar que a finalidade extrafiscal do IPI pode ser utilizada para proteção ambiental, no tocante a onerações e desonerações, sem qualquer tipo de ofensa aos preceitos constitucionais.

Ainda sobre as onerações de impostos com finalidade extrafiscal que contribuem para a proteção do meio ambiente, importante ressaltar a progressividade do ITR. Conforme o art. 153, § 4º , da Constituição ${ }^{45}$, o ITR será progressivo com a finalidade de desestimular a manutenção de propriedades improdutivas, fomentando que a propriedade desempenhe sua função social, que é cumprida quando respeitados os critérios estipulados pelo art. 186 da Carta Política, entre eles, a utilização adequada dos recursos naturais disponíveis e preservação do meio ambiente ${ }^{46}$. Em igual norte, a possibilidade de progressão de alíquota do IPTU, que pode ocorrer por uma série de formas, entre elas a progressividade no tempo, que se dá quando o imóvel não está sendo aproveitado de forma adequada: sob uma ótica ambiental, significa que o imóvel não

42 GONÇALVES, Fernando Dantas Casillo. IPI: inconstitucionalidade da tributação diferenciada para os produtos fabricados com plástico. In: PEIXOTO, Marcelo Magalhães (coord.). IPI: aspectos jurídicos relevantes. São Paulo: Quartier Latin, 2003. p. 91.

43 SOUZA, Jorge Henrique de Oliveira. Op. cit., p. 158.

44 BOTTALLO, Eduardo Domingos. Fundamentos do IPI: imposto sobre produtos industrializados. São Paulo: Revista dos Tribunais, 2002. p. 63-64

45 "Art. 153. [...] $\S 4^{\circ} \mathrm{O}$ imposto previsto no inciso VI do caput: I - será progressivo e terá suas alíquotas fixadas de forma a desestimular a manutenção de propriedades improdutivas." (BRASIL. Constituição (1988). Constituição da República Federativa do Brasil de 1988. Disponível em: <http://www.planalto.gov. br/ccivil_03/constituicao/constituicao.htm >. Acesso em: 7 maio 2015)

46 "Art. 186. A função social é cumprida quando a propriedade rural atende, simultaneamente, segundo critérios e graus de exigência estabelecidos em lei, aos seguintes requisitos: [...] II - utilização adequada dos recursos naturais disponíveis e preservação do meio ambiente." (Idem) 
se encontra em harmonia com princípios do Direito Ambiental e, em uma ótica extrafiscal, tal progressividade contribui para que seja concretizada a função social da propriedade ${ }^{47}$, que inclui a busca por um meio ambiente urbano ecologicamente equilibrado ${ }^{48}$.

Desta feita, é possível perceber que a extrafiscalidade pode ser verificada nas renúncias de receitas, bem como nas onerações dos tributos, principalmente dos impostos, servindo como uma função tributária apta a preservar o meio ambiente, demonstrando que a aplicação de mecanismos econômicos em matéria ambiental resulta no consenso de que o Direito Tributário e as regras da extrafiscalidade são totalmente compatíveis com as finalidades do art. 225 da Constituição.

\section{CONSIDERAÇÕES FINAIS}

Os direitos transindividuais estão amplamente respaldados na Constituição brasileira de 1988. Com o Direito Ambiental não seria diferente, haja vista ser considerado direito transindividual, sendo de todos e competindo a todos sua proteção. Verificou-se que o Direito Ambiental e sua utilidade para com a proteção do meio ambiente são de suma importância para a satisfação da vida em todas as suas formas.

Com o advento de uma Constituição considerada a primeira "Constituição verde", a proteção ambiental passou a ser obrigação de todos e não ficou limitada em dispositivo próprio, ou seja, no art. 225 da Carta. Também está prevista em demais dispositivos constitucionais, por exemplo, no art. 170, que versa sobre a ordem econômica. Do art. 225 é possível extrair típicos princípios do Direito Ambiental, como o princípio do Meio Ambiente Ecologicamente Equilibrado, da Equidade Intergeracional, da Sadia Qualidade de Vida e do Desenvolvimento Sustentável.

No entanto, não são apenas tais princípios que fundamentam a proteção ambiental e limitam a ação humana, pois existem outros mecanismos que auxiliam o intérprete, principalmente quando se está lidando com uma sociedade de risco, na qual as consequências da degradação do meio ambiente são imprevisíveis e imperceptíveis aos sentidos do homem. Com isso, foi possível perceber que o diploma constitucional, no tocante à matéria ambiental, carrega uma lógica de gestão do risco ambiental.

A interação de conjuntos que compõem o meio ambiente e regem a vida em todas as suas formas, demonstram a importância de sua tutela, que não pode

47 BUFFON, Marciano. Op. cit., p. 205.

48 SOUZA, Jorge Henrique de Oliveira. Op. cit., p. 313. 
se limitar nas diretrizes e princípios do Direito Ambiental, cabendo, também, a influência do Direito Tributário, Econômico e Social, compreendendo o Direito Ambiental como disciplina de característica sistêmica.

A partir da ideia de que a proteção do meio ambiente não é restrita à matéria ambiental, bem como a existência do compromisso ético entre o homem e o meio ambiente, operando aquele como agente transformador, foi demonstrado que outros ramos do direito, como o Tributário, possuem mecanismos voltados para a proteção ambiental.

O Direito Tributário expressa o exercício do direito impositivo por meio do Poder Público, retirando compulsoriamente do contribuinte parcela de seu patrimônio, com o objetivo de que o Estado possa alcançar seus fins. No entanto, a referida finalidade fiscal, a partir da instituição do Estado Democrático de Direito, deixa de ser o único fundamento da tributação, pois esta acaba se desvelando não apenas como um mecanismo arrecadatório para suprir os cofres públicos, mas também como instrumento que contribui para construção e efetivação de direitos fundamentais previstos na Constituição Brasileira.

Em um Estado Democrático de Direito, a tributação deixa de estar voltada apenas para suprir as demandas do Estado, passando a ter objetivos indutores de efetivação dos direitos fundamentais, por meio da denominada extrafiscalidade. Ainda que não exista significativo embasamento legal que conceitue a extrafiscalidade, pode-se perceber que é cabível sua utilização para fins de proteção de direitos de terceira dimensão, como é o caso do meio ambiente.

A utilização da tributação sem fins fiscais pode contribuir para preservação ambiental em dois domínios: os benefícios fiscais e as onerações dos impostos. Benefício fiscal é medida de caráter político, econômico e social, com o objetivo de amparar interesses públicos.

As onerações concretizam a extrafiscalidade em prol do meio ambiente quando majoram os impostos incidentes em mercadorias ou produtos que possam vir a prejudicar o meio ambiente. Notou-se que o benefício fiscal se mostra como medida extrafiscal mais eficaz em comparação com as onerações dos impostos extrafiscais, isso porque é mais provável que haja uma mudança comportamental por meio de um benefício do que por meio de uma imposição tributária - oneração.

Independente da forma extrafiscal a ser utilizada, pode-se concluir que não compete ao Direito Tributário se manter inerte frente à necessidade da preservação ambiental, por possuir mecanismos que contribuem para esta, sendo um deles a extrafiscalidade, sem a necessidade de instituir novos tributos. Por fim, a partir da arrecadação com fins protetivos, haverá maior lucratividade do Estado e da sociedade em comparação com a arrecadação às custas da degra- 
dação ambiental, possibilitando que todos os cidadãos tenham efetivamente garantidos seus direitos fundamentais, entre eles o meio ambiente ecologicamente equilibrado.

\section{REFERÊNCIAS}

BERNARDI, Renato. Tributação ecológica: o uso ambiental da extrafiscalidade e da seletividade tributárias. Revista Magister de Direito Ambiental e Urbanístico,

Porto Alegre, v. 3, n. 15, p. 55-76, dez. 2007.

BOBBIO, Norberto. A era dos direitos. Rio de Janeiro: Campus, 1992.

BOTELHO, Werther. Da tributação e sua destinação. Belo Horizonte: Del Rey, 1994.

BOTTALLO, Eduardo Domingos. Fundamentos do IPI: imposto sobre produtos industrializados. São Paulo: Revista dos Tribunais, 2002.

BRASIL. Constituição (1988). Constituição da República Federativa do Brasil de 1988. Disponível em: <http://www.planalto.gov.br/ccivil_03/constituicao/constituicao.htm>. Acesso em: 7 maio 2015.

BUFFON, Marciano. Tributação e dignidade humana: entre os direitos e deveres fundamentais. Porto Alegre: Livraria do Advogado, 2009.

CARDOSO, Tatiana de Almeida Freitas Rodrigues. Por uma tutela efetiva ao meio ambiente: a aplicação da law \& economics para combater a tragédia dos bens comuns. 2012. f. 113. Dissertação de Mestrado pelo Programa de Pós-Graduação em Direito da Universidade do Vale do Rio dos Sinos, São Leopoldo/RS, 2012. Disponível em: <http://biblioteca.asav.org.br/vinculos/000000/000000A1.pdf>. Acesso em: 7 maio 2015.

CARRAZZA, Roque Antônio. A progressividade na ordem tributária. Revista de Direito Tributário, São Paulo, v. 64, p. 43-55, 1994.

CARVALHO, Délton Winter de. Dano ambiental futuro: a responsabilização civil pelo risco ambiental. Rio de Janeiro: Forense Universitária, 2008.

DEUD, Maria Luiza Bello. Extrafiscalidade e políticas públicas de desenvolvimento. Revista Jurídica Empresarial, Porto Alegre, v. 3, n. 18, p. 27-44, jan./fev. 2011.

FAZOLLI, Silvio Alexandre. Princípios ambientais tributários e extrafiscalidade. Revista de Direito Ambiental, São Paulo, n. 34, p. 78-83, 2004.

FIORILLO, Celso Antonio Pacheco. Curso de direito ambiental brasileiro. 13. ed. São Paulo: Saraiva, 2012.

FREITAS, Vladimir Passos de. A Constituição Federal e a efetividade das normas ambientais. 2. ed. São Paulo: Revista dos Tribunais, 2002.

GARCIA, Wander. Direito ambiental. São Paulo: Premier, 2009.

GONÇALVES, Fernando Dantas Casillo. IPI: inconstitucionalidade da tributação diferenciada para os produtos fabricados com plástico. In: PEIXOTO, Marcelo Magalhães (Coord.). IPI: aspectos jurídicos relevantes. São Paulo: Quartier Latin, 2003.

GOUVÊA, Marcus de Freitas. Questões relevantes acerca da extrafiscalidade no direito tributário. Interesse Público, Sapucaia do Sul, n. 34, p. 175-200, 2005. 
HENRIQUES, Elcio Fiori. Os benefícios fiscais no direito financeiro e orçamentário: o gasto tributário no direito brasileiro. São Paulo: Quartier Latin, 2010.

MACHADO, Hugo de Brito. Curso de direito tributário. 31. ed. rev., atual. e ampl. São Paulo: Malheiros, 2010.

MACHADO, Paulo Affonso Leme. Direito ambiental brasileiro. 18. ed. São Paulo: Malheiros, 2010.

MARAFON, Plínio José. IOF. In: MARTINS, Ives Gandra da Silva (coord.). Curso de Direito Tributário. 8. ed. São Paulo: Saraiva, v. 2, 2001.

MARTINS, Ives Gandra da Silva. Teoria da imposição tributária. 2. ed. rev. e atual. São Paulo: LTr, 1998.

MATTHES, Rafael Antonietti. Extrafiscalidade como instrumento de proteção ambiental no Brasil. Veredas do Direito, Belo Horizonte, v. 8, n. 16, p. 47-62, jul./dez. 2011.

NABAIS, José Casalta. O dever fundamental de pagar impostos: contributo para a compreensão constitucional do estado fiscal contemporâneo. Coimbra: Almedina, 2009.

SALIBA, Ricardo Berzosa. Fundamentos do direito tributário ambiental. São Paulo: Quarter Latin, 2005.

SOUZA, James José Marins de; TEODOROVICZ, Jeferson. Extrafiscalidade socioambiental. Revista Tributária e de Finanças Públicas, São Paulo, v. 18, n. 90, p. 73-123, jan./fev. 2010.

SOUZA, Jorge Henrique de Oliveira. Tributação e meio ambiente: as espécies tributárias e sua utilização para alcance de um meio ambiente ecologicamente equilibrado. Belo Horizonte: Del Rey, 2009. 